\title{
Selected Books Received
}

Shubik, Martin and Eric Smith: The Guidance of an Enterprise Economy. 580 pp. MIT Press, London, 2016, Cloth, £54.95.

Chapter 1: The Context of Competition

Chapter 2: Minimal Institutions: Game Theory and Gaming

Chapter 3: Formalizing Measurement and Modeling: The Preinstitutional Society

Chapter 4: Supporting Attainable Solutions: Symmetry and Complexity in One-Period Exchange Mechanisms

Chapter 5: Endogenizing the Choice of a Monetary System

Chapter 6: The Economy: Time, Size and Complexity

Chapter 7: Building Theories of Economic Process

Chapter 8: Uncertainty and Velocity

Chapter 9: Innovation and Breaking the Circular Flow

Chapter 10: Innovation and Evolution: Growth and Control

Chapter 11: Mathematical Institutional Economics and the Theory of Money and Financial Institutions

Chapter 12: Process, Strategy and Behavior

Chapter 13: The Guidance of an Enterprise Economy

Bibliography

Name Index

Subject Index 